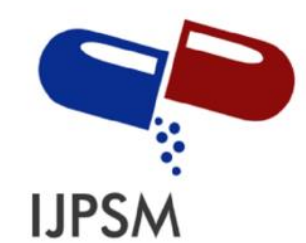

Chouhan Vaishali et al, Int. Journal of Pharmaceutical Sciences and Medicine (IJPSM),

Vol.6 Issue. 8, August- 2021, pg. 104-117

ISSN: 2519-9889

Impact Factor: 3.426

\title{
ANTIANXIETY EFFECT OF ETHANOLIC EXTRACT OF FRUITS OF LIMONIA ACIDISSIMA IN SWISS ALBINO MICE
}

\author{
Chouhan Vaishali*; Sujane Sandhya; Bapna Rajendra; Pyathi Asharani \\ Department of Pharmacology, Swami Vivekanand College Of Pharmacy, Indore (Madhya-Pradesh), India
} DOI: 10.47760/ijpsm.2021.v06i08.007

\begin{abstract}
Anxiety disorder is one of the most common mental ailments exhibited by human. It is characterized by motor tension, sympathetic hyperactivity and apprehension and vigilance syndromes.

A part from very few chemical remedies available like benzodiazepine and serotonin modulators, not much treatment options are at hand that safely and effectively alleviate anxiety. The ethanol extract of the fruits of plant Limonia acidissima was evaluated for its anti-anxiety activity in swiss albino mice at dose $200 \mathrm{mg} / \mathrm{kg}$ and $400 \mathrm{mg} / \mathrm{kg}$ body weight.

Anti-anxiety was assessed by using elevated plus maze (EPM) and light and dark model methods. The ethanolic extract exhibit anxiolytic effect in experimental mice. So it is supports the use of Limonia acidissima as anxiolytic agents. Further investigation should be made to elucidate the active constituent of responsible for the activity.

KEYWORDS: Anxiety, Ethanolic extract, Elevated plus maze, Limonia acidissima.
\end{abstract}

1. INTRODUCTION : Anxiety is psychological and physiological state characterized by somatic, emotional, cognitive, and behavioral component, associated with significant disability, uncomfortable emotional state, negative feelings about the future, or distress that triggers a sense of defense that serves as a warning so that the individual can prepare to face a possibly dangerous situation. ${ }^{[1]}$ Anxiety disorders are psychiatric disorders affecting nearly $25 \%$ of the adult population at some purpose in their life. The prevalence of anxiety disorders is $30.5 \%$ and $19.2 \%$ in women and men respectively. The prevalence of anxiety disorders is remarkably high in young people. Children aged seven to eleven years according a $15.4 \%$ prevalence rate of anxiety disorders. A survey has also stated that less than $14 \%$ of people with such psychiatric disorders receive 


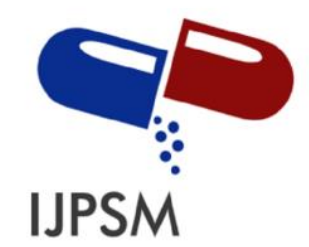

Chouhan Vaishali et al, Int. Journal of Pharmaceutical Sciences and Medicine (IJPSM), Vol.6 Issue. 8, August- 2021, pg. 104-117

ISSN: 2519-9889

Impact Factor: 3.426

treatment. Anxiety can aggravate many physical and mental ailments and also impede recovery from any other problems. ${ }^{[2]}$ Anxiety has become a significant are of psychopharmacological research during this decade, as it affects around one-eighth of the total population of the world.

Plants with medicinal properties have been known for 1000 of years and have been used as traditional medicine by the people to treat diseases. Due to many side effects of drugs of medical science and their high cost, the traditional medicines are being used all over the world. Botanically derived medicines have played an important role in human society throughout history and prehistory.

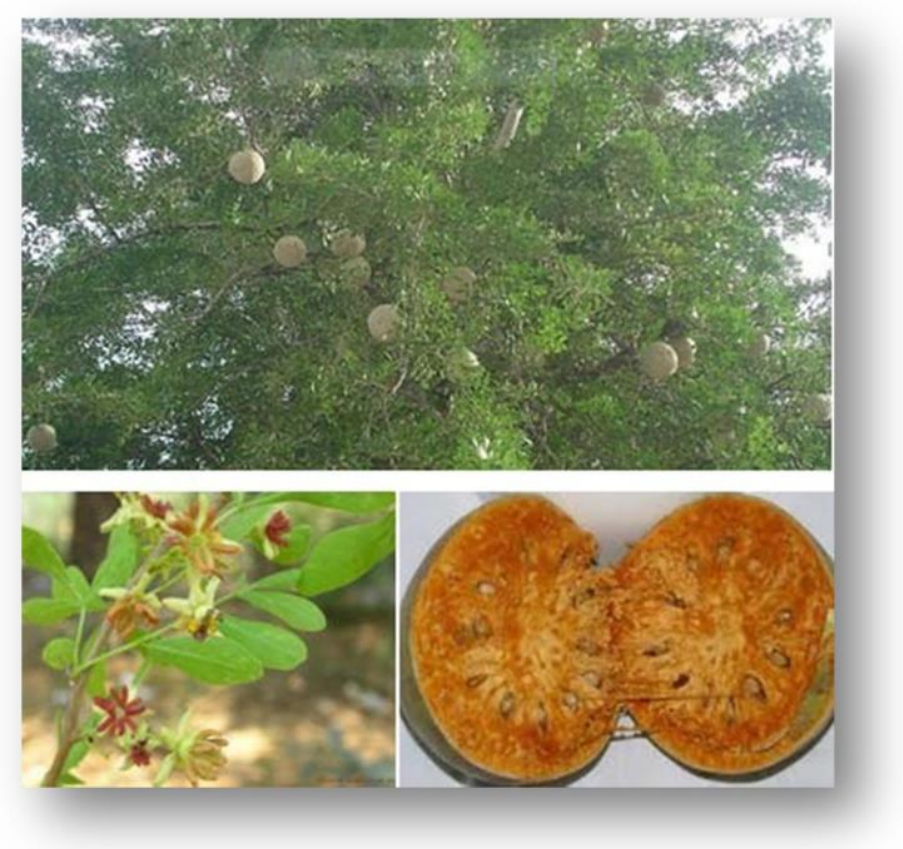

Limonia acidissima L. (wood apple) is a member of the family, Rutaceae and is a religious tree planted in temples and gardens. It is a vital indigenous plant of India known for its medicinal and processing properties which is a moderatesized deciduous tree grown throughout India. It is a large tree growing to 9 meters (30 ft) tall, with rough, spiny bark. The leaves are pinnate, with 5-7 leaflets, each leaflet 25-35 mm long and 10-20 mm wide, with a citrusscent when crushed. The fruit is a berry five- nine cm diameter, and may be sweet or sour. It has a very strong rind which can be difficult to break open, and contains sticky brown pulp and small white seeds. The fruits are woody, rough and used as a substitute for bael in diarrheoa and dysentery. ${ }^{[3]}$ The bark and leaves of the plant are used for vitiated conditions of vata and pita while the fruits are used for tumours, asthma, wounds, cardiac debility and hepatitis.4 And the leaves were reported to possess hepatoprotective effect. The fruit contains flavanoids, glycosides, 


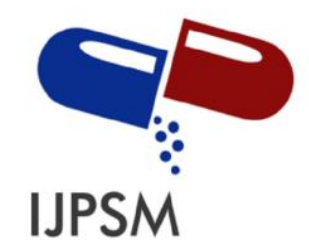

Chouhan Vaishali et al, Int. Journal of Pharmaceutical Sciences and Medicine (IJPSM), Vol.6 Issue. 8, August- 2021, pg. 104-117

ISSN: 2519-9889

Impact Factor: 3.426

saponins and tannins. Some coumarins and tyramine derivatives have also been isolated from the fruits of Limonia. Leaves contain stigmasterol, psoralen, bergapten, orientin, vitedin, saponarin, tannins and an essential oil3. While the fruit shells contain antifungal compounds, namelypsoralene, xanthotoxin, 2, 6-dimethoxybenzoquenone and osthenol. ${ }^{[4]}$

1.1 DISTRIBUTION: Limonia acidissima is native to India and also cultivated in Bangladesh, Pakistan and Srilanka ${ }^{6}$.

1.2 ECOLOGY: The wood-apple is native and common in dry plains. It prefers a monsoon climate with a distinct dry season. The tree grows up to an elevation of $450 \mathrm{~m}$ in the western Himalayas. It is apparently drought tolerant and best adapted to light soils .

$\begin{array}{ll}\text { 1.3 TAXONOMY : Kingdom } & \text { : Plantae } \\ \text { Sub-kingdom } & \text { : Tracheobionta Superdivisio Spermatophyta } \\ \text { Division } & \text { : Magnoliophyta } \\ \text { Class } & \text { : Magnoliospida } \\ \text { Subclass } & \text { : Rosidae } \\ \text { Order } & \text { : Sapindales } \\ \text { Family } & \text { : Rutaceae } \\ \text { Genus } & : \text { Limonia L. } \\ \text { Species } & : \text { L. acidissima. }\end{array}$

1.4 PHYTOCHEMICALS: The preliminary phytochemical analysis of Limonia acidissima plant parts showed the presence of alkaloids, flavonoids, phenols, terpenoids, tannins, fats steroids, saponins, glycosides, gum, mucilage and fixed oils ${ }^{15-18}$. The unripe fruits contain stigmasterol. Fruit pulp contains large quantity of citric acid and other fruit acids, mucilage and 


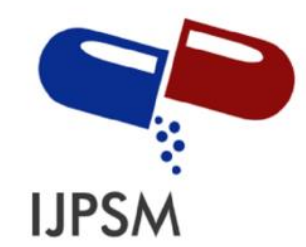

Chouhan Vaishali et al, Int. Journal of Pharmaceutical Sciences and Medicine (IJPSM), Vol.6 Issue. 8, August- 2021, pg. 104-117

ISSN: 2519-9889

Impact Factor: 3.426

minerals. Alkaloids, coumarins, fattyacids and sterols have been detected in the pericarp. It also contains umbelliferone, dictamnine, xanthotoxol, scoparone, xanthotoxin, isopimpinellin, isoimperatorin and $\operatorname{marmin}^{19}$.Leaves contain stigmasterol, psoralen, bergapten, orientin, vitedin, saponarin, tannins and an essential oil ${ }^{20}$. Seeds contain fixed oil, carbohydrates, proteins and amino acids. Roots contain feronia lactone, marmesin and marmin ${ }^{22}$.

\subsection{PHARMACOLOGICAL ACTIVITY:}

1.5.1 Anti Diarrhoeal activity : Plants have various useful chemical constituents which are used in the treatment of diarrhea.The antidiarrhoeal activity and gastrointestinal motility reducing activity of alcoholic and aqueous extract of bark of Limonia acidissima Linn, was evaluated. In the gastrointestinal motility test, the both extracts, showed antidiarrhoeal activity in the concentration of $200 \mathrm{mg} / \mathrm{kg}$ compared with the control group. Ethanolic extract showed significant antidiarrhoeal activity and significantly decreased the propulsion of charcoal meal through the gastro intestinal tract $^{11}$.

1.5.2 Antidiabetic activity : The anti-diabetic activity was performed on the alloxan induced wistar rats by using methanolic extract of fruit pulp of Limonia acidissima. It has been shown that Limonia acidissima extract markedly improved the glucose tolerance in alloxan induced diabetes in rats as compared to control ( $\mathrm{p}<0.01)$. Extract showed dose dependent effect, 200 and 400 $\mathrm{mg} / \mathrm{kg}$ dose shows reduction in glucose level. More over Limonia acidissima extract showed significant reduction in blood urea and creatinine in treated rats but significantly increased total protein level ${ }^{24}$. A significant dose dependent antidiabetic effect of methanolic fruit extract ${ }^{25}$ and aqueous leaf extract ${ }^{26}$ of Limonia in streptozotocin induced diabetic rats have been well documented.

1.5.3 Wound healing: Albino rates of either sex were used to check the wound healing activity by screening with methanol extract of fruit pulp of $L$. acidissima. In the excision wound 


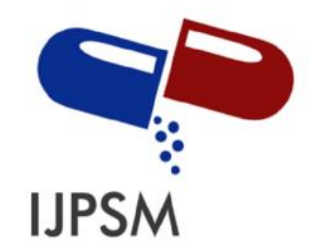

Chouhan Vaishali et al, Int. Journal of Pharmaceutical Sciences and Medicine (IJPSM), Vol.6 Issue. 8, August- 2021, pg. 104-117

ISSN: 2519-9889

Impact Factor: 3.426

model, the wound contracted progressively when treated with the extracts and required a mean period of $16.0 \pm 0.8$ days for optimum healing. Incision wound model showed increased wound breaking strength and decreased epithelization period when treated with MELA ${ }^{27}$.Different extracts of $L$. acidissima possesses significant dose- dependent wound healing activity; this supports traditional claims for the plant as a wound healer.

1.5.4 Anticancer activity: The fruit extract of L. acidissima Linn. shows anticancer effect ${ }^{28}$. Fruit extracts from fractions 1 to 4 and also the crude extract (ethanolic extract) were used to determine the ED50 value (50\% inhibition of cancer cell growth) in two different breast cancer cell lines, SKBR3 and MDA- MB-435. The bio-assays of extracts from L. acidissima Linn. showedthat afraction(fraction3) froman ethanolic extract had an anticancereffect on SKBR3 and MDA-MB- 435 human breast cancer cells. After $48 \mathrm{~h}$ of exposure, this fraction at a concentration of $100 \mu \mathrm{g} / \mathrm{ml}$, significantly reduced cell proliferation in both cancer cells. In MDA - MB-435 cells, cell cycle analysis showed that the fruit extract fraction 3 induced the accumulation of cells in $\mathrm{G}_{2} / \mathrm{M}$ phase, whereas no significant change in cell cycle was detected in SKBR3 cells ${ }^{29}$.

1.5.5 Antioxidative property: The crude methanol extract of the stem bark of Limonia acidissima L. and its different organic soluble partitionates were screened for antioxidant activities ${ }^{30}$. The antioxidant (free radical scavenging) activity of the partitionates on the stable radical 1,1 -diphenyl-2- picrylhydrazyl (DPPH) was determined. The chloroform soluble fraction (CL) of crude methanolic extract showed the highest free radical scavenging activity. At the same time the pet ether soluble fract ion (PE) also exhibited strong antioxidant potential. The methanolic extract of Limonia fruit was also screened for their free radical scavenging properties by Ferric reducing antioxidant power (FRAP) assay and DPPH radical scavenging assay ${ }^{31}$. In vitro antioxidant activity of different extracts from leaves of Limonia acidissima has been well documented ${ }^{32,33}$. 


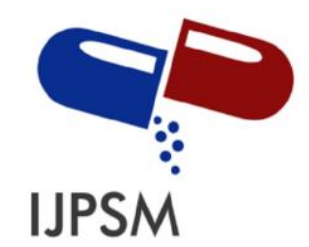

Chouhan Vaishali et al, Int. Journal of Pharmaceutical Sciences and Medicine (IJPSM), Vol.6 Issue. 8, August- 2021, pg. 104-117

ISSN: 2519-9889

Impact Factor: 3.426

1.5.6 Hepatoprotective: Hepatoprotective activity of them ethanolic extract of fruit pulp of L. acidissima (MELA) was investigated against carbon tetra chloride $\left(\mathrm{CCl}_{4}\right)$ induced hepatic injury in rats. 200 and $400 \mathrm{mg} / \mathrm{kg}$ p.o doses of MELA were administered to group of animals for 10 days. MELA exhibited significant dose dependant protective effect against $\mathrm{CCl}_{4}$ induced liver damage which can be mainly attributed to the antioxidant property of the extract. This study rationalized the ethno-medicinal use of the plant for curing hepatic injuries ${ }^{27}$.

1.5.7 Biosorbent : The waste fruit shell of Limonia acidissima is used as a biosorbent. The powdered raw material and treate $d$ material (raw material treated with acid) of specific micron size were used for the removal of the methylene blue from aqueous solution. The results showed that the removal of dye by chemically treated material is effective than raw material at higher te mperature. Temperature rise affects the solubility and chemical potential of the adsorption, the latter being a controlling factor for adsorption. The percentage removal of dye is maximum at $35^{\circ} \mathrm{C}$ for treated material and at $25{ }^{\circ} \mathrm{C}$ for raw material ${ }^{34}$.

1.5.8 Diuretic Agent: Diuretic activity of methanolic extracts obtained through the Microwave assisted extraction (MAE) and Bath Sonicator extraction (BSE) of Limonia acidissima was investigated. The extract (obtained through the BSE) produced a significant increase $(\mathrm{P}<0.001)$ in urine output at the same dose. Urinary electrolyte extraction was also affected by the extract (obtained through the MAE) increase the urinary excretion of Sodium, potassium and chloride ions. These findings support the traditional uses of Limonia acidissima leaves as diuretic agents ${ }^{35}$.

1.5.9 Antibacterial activity: It was found that ethanolic extract of Limonia acidissima $\mathrm{L}$. leaves possess abroad spectrum of activity against Gram-positive and Gram-negative bacterial strains responsible for the most common bacterial diseases ${ }^{36,18,15}$. The antibacterial activity was evaluated against Gram-negative and Gram-positive bacteria by agar well diffusion method. Methanol extract showed good antibacterial activity with the high inhibition zones while chloroform extract exhibited mild to moderate activity and hexane extract was found to be less 


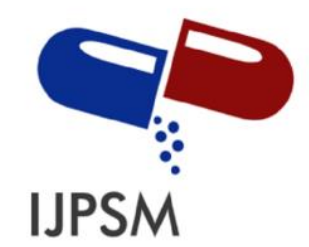

Chouhan Vaishali et al, Int. Journal of Pharmaceutical Sciences and Medicine (IJPSM), Vol.6 Issue. 8, August- 2021, pg. 104-117

ISSN: 2519-9889

Impact Factor: 3.426

active $^{37}$.

1.5.10 Antifungal Activity : The different extracts (petroleum ether, chloroform, methanol and aqueous) of Feronia limonia Linn fruit pulp exhibited antifungal activity against some pathogenic fungus ${ }^{16}$.The essential oil from the leaves of the plant exhibited antifungal activity against eight testedfungi ${ }^{38}$.

1.5.11 Antispermatogenic activity : Ethanolic extract of fruit pulp of $F$. limonia impair reproductive activities in male rats possibly by inhibiting spermatogenesis. It was found that administration of this extract to male rats brought about a significant weight loss of the reproductive organs of the rats, alterations in motility, viability and morphology of spermatozoa. From whole study it was finally concluded that Feronia limonia fruit pulp may have reversible antispermatogenic activity, and could then partially support the scientific rationale for the traditional use of this plant in inducing sterility in male ${ }^{39}$.

1.5.12 Antihistaminic activity : Ethanol extract of Feronia elephantum bark significantly inhibited clonidine-induced catalepsy. Clonidine releases histamine from mast cells which is responsible for different asthmatic conditions. Catalepsy produced by clonidine is mediated by histamine via $\mathrm{H}_{1}$ receptor. Thus it is concluded that ethanol extract of bark of Feronia elephantum has antihistaminic effect ${ }^{40}$.

1.5.13 Antilarvicidal Activity : Acetone extract of the dried leaves found to be effective against larvae of Culexquinque fasciatus, Anopheles stephensi and Aedesaegypti, with $\mathrm{LC}_{50}$ of 129.24, 79.58 and 57.23 ppm, respectively ${ }^{41}$. 


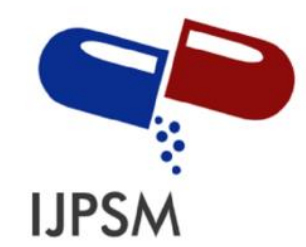

Chouhan Vaishali et al, Int. Journal of Pharmaceutical Sciences and Medicine (IJPSM), Vol.6 Issue. 8, August- 2021, pg. 104-117

ISSN: 2519-9889

Impact Factor: 3.426

\section{MATERIALS AND METHODS}

2.1 Plant material: Fruits of Limonia Acidissima were collected from Dharnaka Mhow, Indore (M.P.) India.

2.2 Treatment of plant part: The fruits of the plant were cleaned, dried under shade and powdered by a mechanical grinder.

2.3 Preparation of ethanolic extract: Hundred grams of coarsely power of fruits was defatted with petroleum ether using soxhlet apparatus. The defatted marc was further extract with ethanol using soxhlet and the extract obtained was concentrated using rotary evaporator. Then, the percentage yield of extracts was $15 \mathrm{~g}$ and stored in a desiccator.

2.4 Phytochemical tests: For the phytochemical investigation, $1 \%$ of aqueous extract of each extract was used following methods for phytochemical screenings were applied on extract.

\section{a) Carbohydrates}

Fehling's test; $1 \mathrm{ml}$ Fehling's A solution and $1 \mathrm{ml}$ Fehling's B solution were mixed and boiled it for 1 minute. Now the equal volume of test solution was added to above mixture. The solution was heated in water bath for 5-10 minutes. First yellow and then brick red precipitate was obtained. This confirmed the presence of sugar.

\section{b) Flavone Glycosides}

Molisch test; $2 \mathrm{ml}$ of test solution is placed in test tube. 2 drops of Molisch reagent (a solution of $\alpha$-napthol in 95\% ethanol) was added. The solution was poured slowly into a tube which contained $2 \mathrm{ml}$ of sulphuric acid then two layers was formed. There was formation of purple product at the interface of the two layers. 


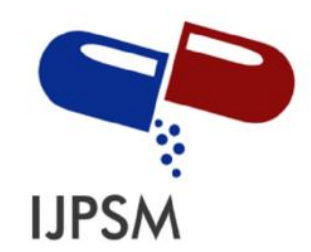

Chouhan Vaishali et al, Int. Journal of Pharmaceutical Sciences and Medicine (IJPSM), Vol.6 Issue. 8, August- 2021, pg. 104-117

ISSN: 2519-9889

Impact Factor: 3.426

\section{c) Flavonoids}

On addition of an increasing amount of sodium hydroxide, the extract was shown yellow coloration; this was decolorized after addition of dilute hydrochloric acid.

\section{d) Steroids and Triterpenoids}

Salkowski Test; Treat the extract with few drops of concentrated sulphuric acid, red color at lower layer indicates presence of steroid and formation of yellow color lower layer indicates presence of Triterpenoids.

\section{e) Alkaloids}

Mayer's test: To $2 \mathrm{ml}$ of palnt extract, $2 \mathrm{ml}$ of concentrated hydrochloric acid was added. Then, few drops of mayer's reagent were added. The presence of green or white precipitate indicated the presence of alkaloids.

\section{f) Tannins and Phenols}

Ferric chloride Test: To $3 \mathrm{ml}$ of extract, $3 \mathrm{ml}$ of $5 \% \mathrm{w} / \mathrm{v}$ ferric chloride solution was added. The blue - black color indicates the presence of tannins and phenols.

\section{g) Test for Saponins}

Foam Test: The extract $(2 \mathrm{~g})$ was shaken vigorously with $20 \mathrm{ml}$ of water and observed for persistent foam, which indicates the presence of saponins. 


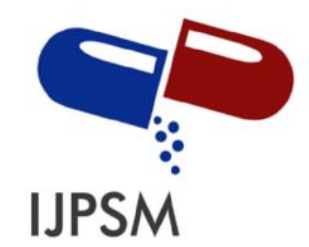

Chouhan Vaishali et al, Int. Journal of Pharmaceutical Sciences and Medicine (IJPSM), Vol.6 Issue. 8, August- 2021, pg. 104-117

ISSN: 2519-9889

Impact Factor: 3.426

3 EXPERIMENTAL ANIMAL: Swiss albino mice (males; 20-25 g) were produced from disease free small animal house, Swami Vivekanand College of pharmacy, Indore M.P. (India). Since, estrogen are the female sex hormones, found to have neuroprotective effect, therefore, we have excluded female mice and used only male mice for the present of study. The mice were kept at constant temperature $\left(22 \pm 2^{\circ} \mathrm{C}\right)$ and 12-h light and 12-h dark. Mice were fed standard laboratory food and water was given ad libitum. The animal were acclimatized to the laboratory condition before experimental. Experiments were carried out between 09:00 AM- 04:00 PM. The experimental protocol was approved by Institutional Animals Ethics Committee (IAEC), Care of the animals was taken as per guidelines of the Committee for the Purpose of Control and Supervision of Experiments on Animal (CPCSEA), Government of India, New Delhi. (Registration No. 1839/OP/ERe/S/15/CPCSEA).

3.1 Acute toxicity study: Acute toxicity study procedure was followed as per OECD 423 guidelines. The Limonia Acidissima ethanolic extract was administered orally at the dose of $500 \mathrm{mg} / \mathrm{kg}, 1500 \mathrm{mg} / \mathrm{kg}, 2000 \mathrm{mg} / \mathrm{kg}$ and $2500 \mathrm{mg} / \mathrm{kg}$. Control group of administered saline $\left(10 \mathrm{ml} / \mathrm{kg}\right.$ of animal). The literature search of conventional $\mathrm{LD}_{50}$ test shown not any sing of toxicity or mortality was observed at the higher dose of $2000 \mathrm{mg} / \mathrm{kg}$ during the observation for mortality up to $48 \mathrm{hrs}$. After administration of the doses. During the acute toxicity study, animal were observed for 14 days to study their behavior neurological toxicity. 


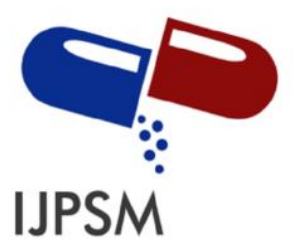

Chouhan Vaishali et al, Int. Journal of Pharmaceutical Sciences and Medicine (IJPSM), Vol.6 Issue. 8, August- 2021, pg. 104-117

ISSN: 2519-9889

Impact Factor: 3.426

\subsection{Methods:}

3.2.1 Elevated Plus maze : The plus maze apparatus consisted of two open arms, measuring

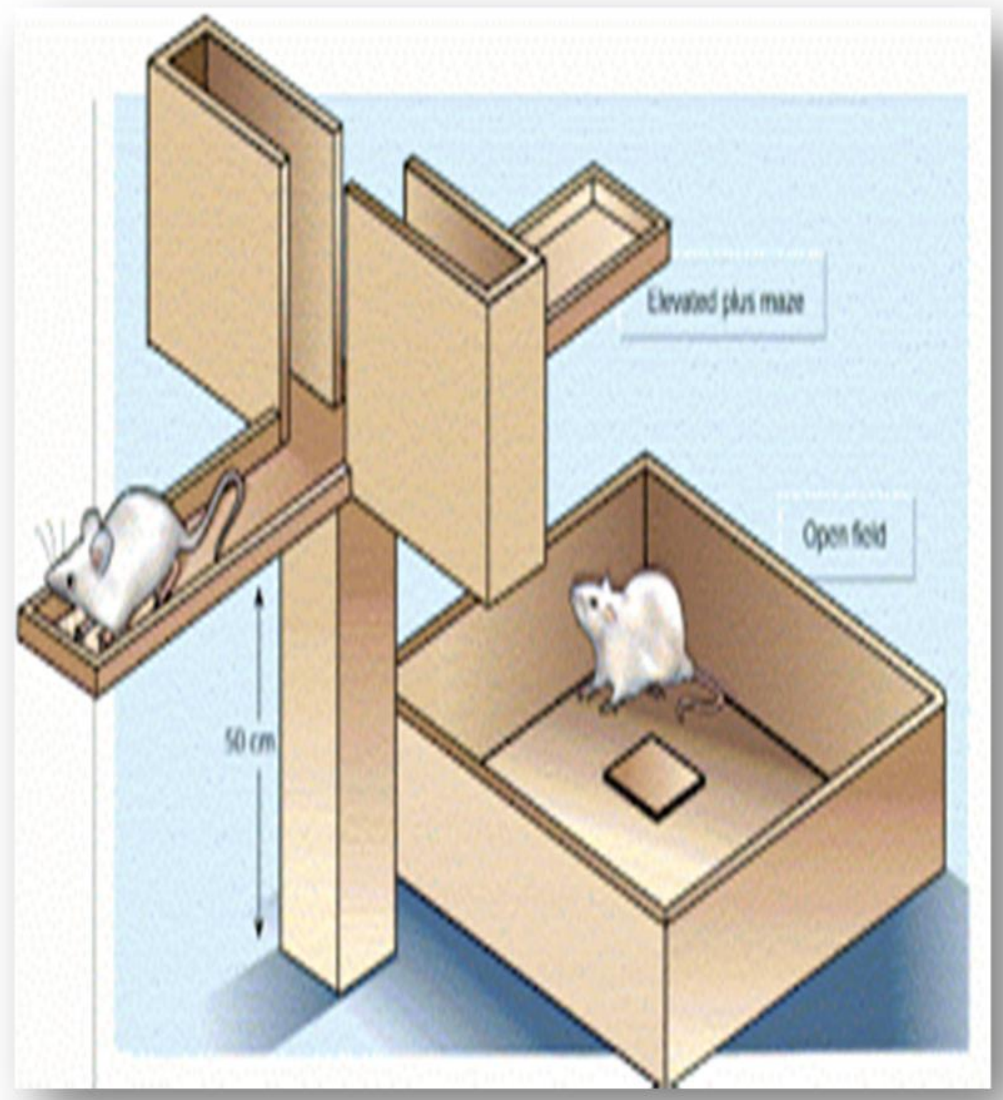

$(16 \times 5 \mathrm{~cm})$, and two closed arms, measuring $(16 \times 5 \times 12 \mathrm{~cm})$, and an open roof with the entire maze elevated $(25 \mathrm{~cm})$ from the floor. Swiss albino mice $20-25 \mathrm{~g}$ was treated with normal saline, diazepam, extract $30 \mathrm{~min}$ before being placed individually in the center of elevated plus maze, facing a closed arm. The spent in bath open and closed arms was recorded for $5 \mathrm{~min}$. the time spent was measured in seconds. The numbers of entries into the open and closed arms were counted during the test. An entry was defined as having all four paws with the arm. 


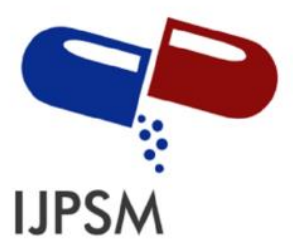

Chouhan Vaishali et al, Int. Journal of Pharmaceutical Sciences and Medicine (IJPSM), Vol.6 Issue. 8, August- 2021, pg. 104-117

ISSN: 2519-9889

Impact Factor: 3.426

3.2.2 Light and Dark Model : The Light and dark apparatus consisted of open top wooden

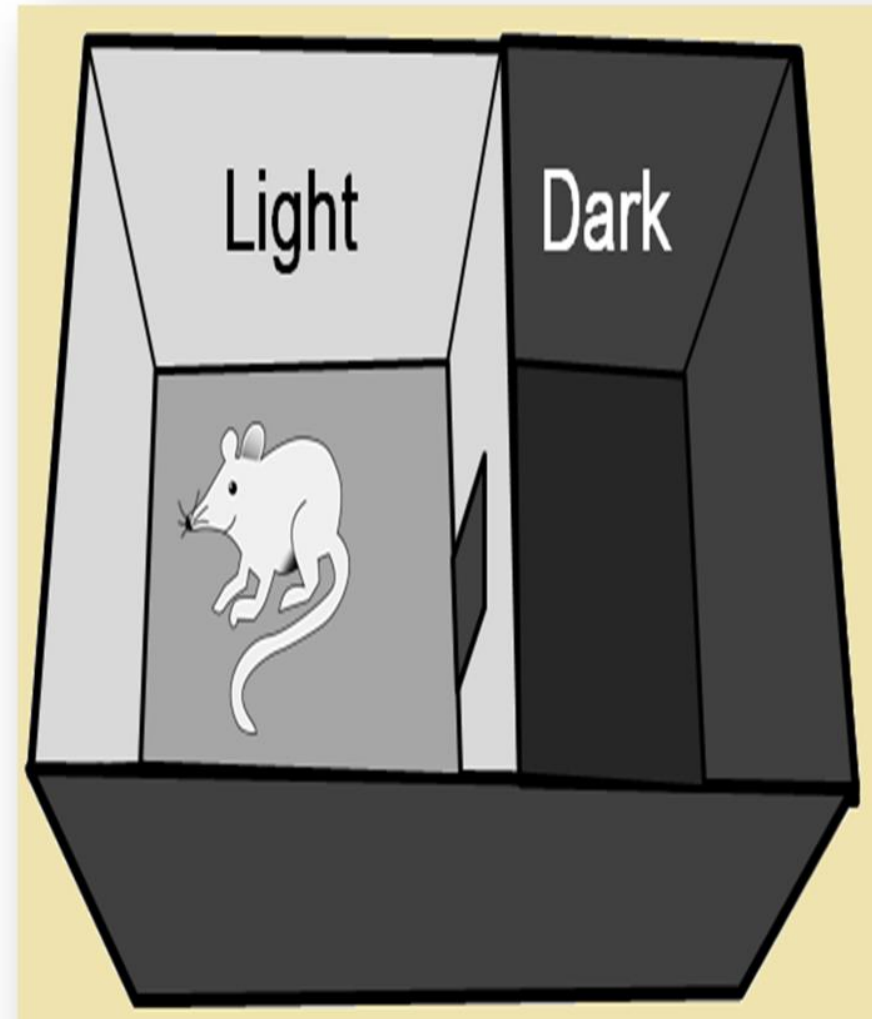
box. Two distinct chambers, a black chamber $(25 \mathrm{~cm}$ long $\times 35 \mathrm{~cm}$ wide $\times 35 \mathrm{~cm}$ deep), painted black and made dark by covering its top with black plywood, and a bright chamber $(25 \mathrm{~cm} \quad$ long $\times 35 \mathrm{~cm}$ wide $\times 35 \mathrm{~cm}$ deep), painted white and brightly illuminated with $40-\mathrm{W}$ white light source, were placed 25 $\mathrm{cm}$ above the open box. Two chamber were connected through a small open doorway $(7.5 \mathrm{~cm}$ long $x 7.5 \mathrm{~cm}$ wide) situated on the floor level at the center of the partition. The mice were placed individually in the center of the light box after $30 \mathrm{~min}$ of oral treatment and observed for $5 \mathrm{~min}$.

4 CONCLUSION: Anti-anxiety activity perform by elevated plus maze model and light-dark model. Diazepam are taken as standard reference drug. All the extract have been shown a significant activity when compared to control it concluded that active constituents responsible for anti- anxiety activity might be present in the leaf extracts. However, further studies are necessary to find the exact mechanism of anxiolytic effect and to isolate the active compound(s) responsible for this pharmacological activity. 


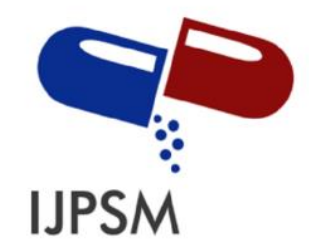

Chouhan Vaishali et al, Int. Journal of Pharmaceutical Sciences and Medicine (IJPSM), Vol.6 Issue. 8, August- 2021, pg. 104-117

ISSN: 2519-9889

Impact Factor: 3.426

\section{REFERENCES}

1. R. C. Kessler, W. T. Chiu, O. Demler, Prevalence, severity, and co-morbidity of 12-month DSM- IV disorders in the National Co morbidity Survey Replication, Arch Gen Psychiatry, 62, 2005, 617-27.

2. G. Simon, J. Ormel, M. VonKorff and W. Barlow, Health care costs associated with depressive and anxiety disorders in primary care, American Journal of Psychiatry, 152, 1991, 352-357.

3. Arya Ashwani, Kumar Tarun, Malik Ajay, Hooda Anil, Anxiety disorders: A review, IRJCP, 2(5), 2011, 18-23.

4. Anxiolytic and hypnotic drugs, in H. P. Rang, Rang and Dale's Pharmacology, 7 (Spain: Elsevier Churchill, 2012) $531-538$.

5. M. Lader, S. Morton. Benzodiazepine problems. Br J Addict, 83, 1991, 823-828.

6. K. Suresh, S. Anupam, Apigenin: The anxiolytic constituent of Turnera aphrodisiaca, Pharm Biol, 44, 2006, 84-90.

7. R. L. Macdonald, R. W. Olsen, GABAA receptor channels, Annu. Rev. Neurosci., 17, 1994, 569-602.

8. Singh Rudra Pratab, Experimental studies on Antianxiety activity of Hydro alcoholic extract of plant.

9. V. Nohria, E. Giller, Ganaxolone, Neurotherapeutics, 4, 2007, 102-105.

10. Chopra RN, Nayar SL, and Chopra IC, Glossary of Indian Medical plant, CSIR publication New Delhi, 2002. P. No. 58-59.

11. Kapoor LD Handbook of Ayurvedic medicinal plant, CRC press, New Delhi, 2001 P. No. 112.

12. S. Kasper, Social Phobia: The nature of the disorder, J Affect Disord, 50, 1998, S3-9.

13. Kessler RC, Chiu WT, Demler O, Merikangas KR, Walters EE. Prevalence, severity and comorbidity of 12 month DSM-IV disorders in the National Comorbidity Survey Replication. Arch Gen Psychiatry 2005; 62:617-627.

14. Schulz V, Hansel R, Tyler VE. Rational phytotherapy: a physician's guide to herbal medicine. Berlin:Springer Verlag, 2001.

15. Lader M, Tylee A, Donoghue J. Withdrawing benzodiazepines in primary care. CNS Drugs. 2009; 23 (1): 19 - 34.

16. Montenegro M, Veiga H, Deslandes A. Neuro-modulatory effects of caffeine and bromazepam on visual eventrelated potential (P300): a comparative study. Arq Neuropsiquiatr. 2005; 63 (2): 410 - 5.

17. http://www.ncbi.nlm.nih.gov/pubmed/12652886.

18. Owen RT. Pregabalin: its efficacy, safety and tolerability profile in generalized anxiety. Drugs Today. 2007; 43 (9): $601-10$.

19. http://www.scielo.br/pdf/bjmbr/v39n4/6164.pdf

20. Ernst E. Herbal remedies for anxiety - a systematic review of controlled clinical trials. Phytomedicine. 2006; 13 (3): $205-8$.

21. Shephard RA. Behavioral effects of GABA agonists in relation to anxiety and benzodiazepine action. Life Sci. 1987; 40 (25): 2429 - 36.

22. Foster AC, Kemp JA. Glutamate- and GABA-based CNS therapeutics. Curr Opin Pharmacol. 2006; 6 (1): 7

23. Vijayvargia P, Vijayvergia R Review on Limonia acidissima 1.: Multipotential Medicinal Plant, Plant Pathology and Biochemistry Laboratory, Department of Botany, University of Rajasthan, Jaipur, India 2014; (36) 191-195.

24. Vijayvargia P, Choudhary S, Vijayvergia R. Preliminary phytochemical screening of Limonia acidissima Linn. Int J Pharm PharmSci, 6, 2014, 134-136.

25. Vaidya A B D, Devasagayam T P A, Current status of herbal Drugs in India, J. Clin. Biochem. Nutr., 2007;41(1):111

26. Malviya R, Kumar A, Singh A, Kulkarni GT. Pharmacological Screening, Ayurvedic values and Commercial Utility of Aegle Marmelos. International Journal of Drug Development \& Research, 2012, 4.

27. Ilango K,Chitra V .Hepatoprotective and Antioxidant Activities of Fruit pulp of Limonia acidissima Linn. Int J 


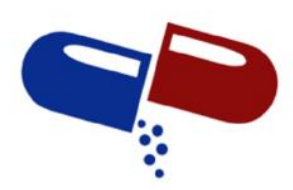

IJPSM

Chouhan Vaishali et al, Int. Journal of Pharmaceutical Sciences and Medicine (IJPSM), Vol.6 Issue. 8, August- 2021, pg. 104-117

ISSN: 2519-9889

Impact Factor: 3.426

Health Res, 2, 2009, 361-367.

28. Ennaceur, A (2013). "Tests of unconditioned anxiety - Pitfalls and disappointments". Physiology \& Behavior. 135: 55-71

29. Bourin, M; Hascoet, M (2003). "The mouse light/dark box test". European Journal of Pharmacology. 463: 55-65

30. Neuropathol Exp Neurol. 75 (7): 636-55

31. Pellow, S., Chopin, P., File, S.E. and Briley, M. (1985). "Validation of open:closed arm entries in an elevated plusmaze as a measure of anxiety in the rat". J. Neurosci. Methods. 14 (3): 149-67. 